Portland State University

PDXScholar

1990

\title{
A Comparison of an Acoustic Stethoscope and an Amplified Stethoscope in White Noise and Cafeteria Noise During Cardiac Auscultation
}

Lynda Lynell Gigstad

Portland State University

Follow this and additional works at: https://pdxscholar.library.pdx.edu/open_access_etds

Part of the Cardiovascular System Commons, and the Speech Pathology and Audiology Commons Let us know how access to this document benefits you.

Recommended Citation

Gigstad, Lynda Lynell, "A Comparison of an Acoustic Stethoscope and an Amplified Stethoscope in White Noise and Cafeteria Noise During Cardiac Auscultation" (1990). Dissertations and Theses. Paper 3974. https://doi.org/10.15760/etd.5855

This Thesis is brought to you for free and open access. It has been accepted for inclusion in Dissertations and Theses by an authorized administrator of PDXScholar. Please contact us if we can make this document more accessible: pdxscholar@pdx.edu. 
AN ABStRACT OF THE THESIS OF Lynda Lynell Gigstad for the Master of science in speech communication with emphasis in Audiology presented August $23,1990$.

Title:

A Comparison of an Acoustic stethoscope and an Amplified stethoscope in White Noise and Cafeteria Noise during Cardiac Auscultation.

APPROVED BY MEMBERS OF THE THESIS COMMITTEE:

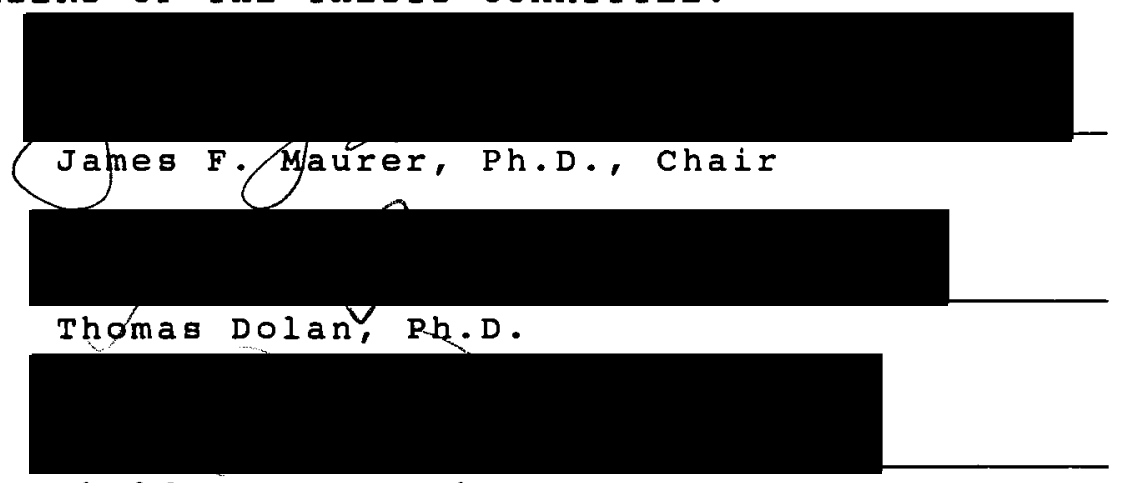

Sheldon Maron, Ph.D.

A basic relationship between stethoscopic auscultation and background noise interference was reviewed and examined in this study. The principle experimental design of the study questioned whether hospital background noise levels are capable of masking the threshold of detection for auscultated heart sounds. Several cited studies monitoring background noise levels in various hospital locations have reported averages exceeding the U.S. Environmental Protection Agency (EPA) (1974) and world Health organization 
(WHO) (1980) recommendations of "quiet", namely 35 to 40 dBA (Falk \& Woods, 1973; Hilton, 1985, 1987; Shapiro \& Berland, 1972; Turner, et al., 1975; Woods \& Falk, 1974) by as much as 46 to $51 \mathrm{~dB}$, i.e., up to 86 dBA (Shapiro \& Berland 1972). In addition to the previous query, a review of the literature reflected a lack of implementatory standards regarding the acoustic stethoscopic output and the masking effects of noise during the auscultation process. specifically, this study ascertained the effective masking level (EML) intensities of two noise environments, white noise and cafeteria noise, for cardiac auscultation through an acoustic stethoscope and an amplified stethoscope. Two principle measurements were employed in the experimental protocol: an objective measurement employing a method of adjustment detection identification task of the EML, and subjective responses solicited by a forced-choice questionnaire. Sixteen normal hearing listener's were selected to participate in the experiment. Objective measures were analyzed using a MANOVA and a Pearson Product Moment coefficient of Correlation. The subjective questionnaire data were analyzed with a two-tailed T-test. All analyses were based on a .05 level of confidence.

The resultant analysis of the experimental protocol data revealed calculated EML means greater than 92 dBA for both of the stethoscopes and the noise environments. These 
findings did not support the primary hypothesis which stated that there would be a relatively low, 65 to 75 dBA, EMI for the two noise environments. Based on the these findings and previous noise studies, most hospital settings appear to provide a listening environment that will not completely mask the detection threshold of cardiac sounds during auscultation.

In addition, there were no significant differences demonstrated for the stethoscopes or the noise environments. This could be interpreted that the sprague-Rapport LAB 600 acoustic stethoscope and the Bosch EST 40 amplified stethoscope function equally well for the detection purposes in high intensity, $90+d B A$, noise environments. subsequently, at these high levels, there appears to be no discernable difference between the absolute masking effect of white noige and cafeteria noise. The questionnaire data results also found that there was no discernable difference between the subjective performance of the stethoscopes. Both stethoscoper were judged to perform equally well in the areas of comfortable loudness, quality and clearness of sound transmission, noise attenuation in both white noise and cafeteria noise, and goodness of ear tip fit. 


\title{
A COMPARISON OF
}

AN ÁCOUSTIC STEThOSCOPE AND AN AMPLIFIED STEThOSCOPE IN WHITE NOISE AND CAFETERIA NOISE DURING CARDIAC AUSCULTATION

by

LYNDA LYNELL GIGSTAD

A thesis submitted in partial fulfillment of the requirements for the degree of

\author{
MASTER OF SCIENCE \\ in \\ SPEECH COMMUNICATION: \\ SPEECH AND HEARING SCIENCES
}

Portland state University

1990 
TO THE OFFICE OF GRADUATE STUDIES:

The members of the Committee approve the thesis of

Lynda Lynell Gigstad presented August $23,1990$.
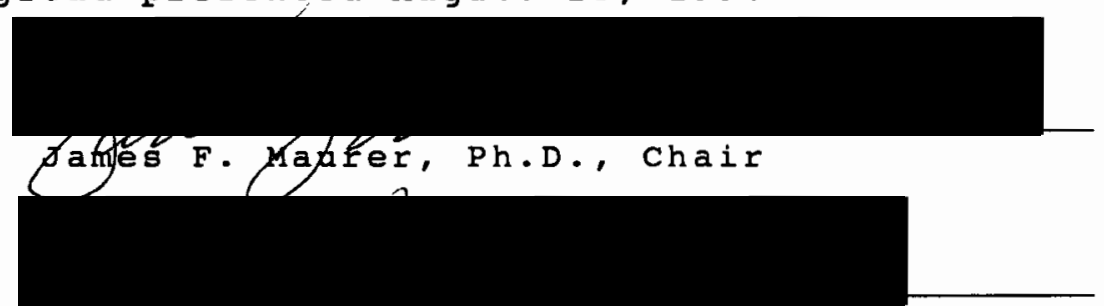

Thomas Dolan, Ph.D.

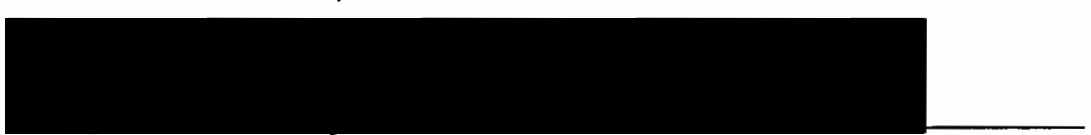

Sheldon Maron, Ph.D.

APPROVED :
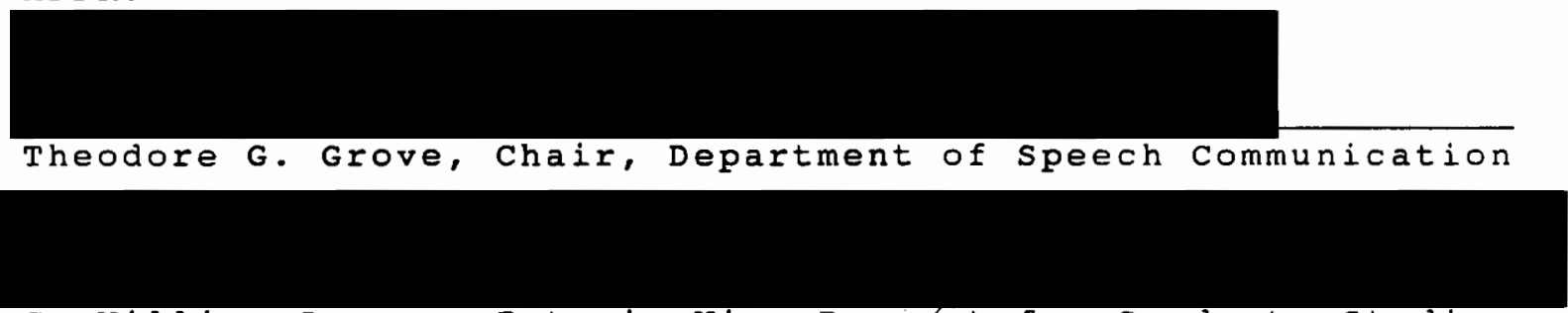

C. William savery, Interim Vice Provost for Graduate studies and Research 


\section{ACKNOWLEDGEMENTS}

At this time, I wish to express my sincere gratitude and appreciation to all of the individuals that shared their time and expertise in order to support and assist in the completion of my research project.

I would like to thank my committee members who guided me throughout each thesis endeavor: Dr. James Maurer (chair), Dr. Thomas Dolan and Dr. Sheldon Maron.

I wish to thank all of the attentive listeners that participated in my study. In particular, John Fitzpatrick who participated as my "heart beat" assistant, and Lois Hagstrom who participated in my pilot study.

A special thanks to all of my resource specialists: Jon Gigstad (Computer Consultant), Anna Mette Smeenk (Experienced Auscultator), Gordon Frey (Electronic specialist), and Theodore Grove (statistician). Finally, a very special thankyou to my parents, relatives, friends and colleagues. With their support and encouragement, I finally accomplished this goal. 
TABLE OF CONTENTS

PAGE

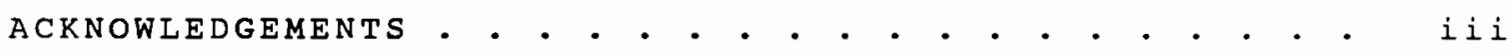

IIST OF TABLES

LIST OF FIGURES

CHAPTER

I INTRODUCTION

I I REVIEW OF THE LITERATURE $\quad \cdot \quad \cdot \quad \cdot \quad \cdot \quad \cdot \quad \cdot \quad \cdot \quad \cdot \quad 10$

Acoustic stethoscope . . . . . . . . . 11

Amplified stethoscope . . . . . . . . 13

stethoscopic Research . . . . . . . . . 15

Human Hearing . . . . . . . . . . . 17

Heart sounds . . . . . . . . . . . . . 20

Background Noise . . . . . . . . . . . 21

Clinical Background Noise......... . 22

Background Noise and Auscultation . . . 23

Statement of the Problem . . . . . . 26

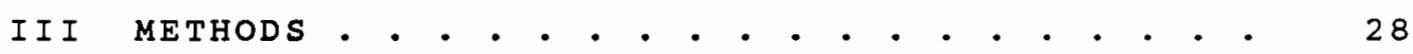

subjects . . . . . . . . . . . . . . 28

Instrumentation . . . . . . . . . . 30

Calibration... . . . . . . . . . . 32

Procedures . . . . . . . . . . . . . . 32 
Data Measurement and Analysis . . . . . . 36

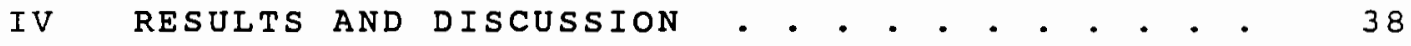

Results • • • • • • • • • • • • • .

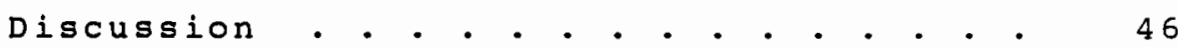

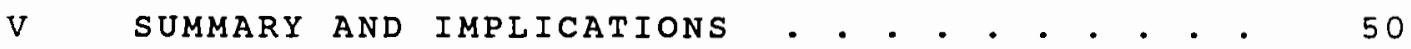

summary $\quad \cdot \quad \cdot \quad \cdot \quad \cdot \quad \cdot \quad \cdot \quad \cdot \quad \cdot \quad \cdot \quad \cdot \quad \cdot \quad \cdot \quad 50$

$\operatorname{Implications}$. . . . . . . . . . . . 52

REFERENCES •

APPENDICES

STETHOSCOPIC QUESTIONNAIRE

59

B

INEORMED CONSENT 


\section{LIST OF TABLES}

TABLE

PAGE

I

I I

I I I

IV

$\mathrm{V}$

V I

Survey of Hospital Background Noise. . . . 24 Mean dBA Data Comparison for stethoscopes and Noise . . . . . . . . . . . . 39 Multivariate Analysis of Variance (MANOVA):

A Comparison of Stethoscopes, Noise and Methods . . . . . . . . . . 42

Pearson Product Moment coefficient of Correlation: (Pearson r) . . . . . . 43 Mean Data Results of Listener Judgements on Stethoscopic Questionnaire . . . . . 44 Dependent Two-Tailed T-Test Analysis of I istener Judgements on a stethoscopic Questionnaire. . . . . . . . . . . . 45 


\section{LIST OF FIGURES}

F I GURE

PAGE

1. Three Weighting scale Networks . . . . . . . . 6

2. Mean output of Three stethoscopes . . . . . . 16

3. Human Dynamic Range of Audition . . . . . . 18

4. Listener's Mean Thresholds of Audibility. . . 29

5. Schematic Representation of Equipment . • . . 31

6. Overhead View of Experimental Arrangement . . 34

7. Mean Effective Masking Levels for an Acoustic stethoscope and an Amplified stethoscope in White Noise and Cafeteria Noise . . . . . 40 
CHAPTER I

INTRODUCTION

Cardiac sounds reflect heart functions. Since the early $1800^{\prime}$ s, the awareness of heart sounds and their possible diagnostic implications have been acknowledged. Gradually over the centuries, heart sound monitoring via a stethoscope has become a common practice. This monitoring process is dependent on the listener's hearing acuity which enables her to auditorily perceive the subtle diagnostically significant differences between normal and aberrant heart sounds. Unfortunately, this perception is also limited by a minimal overlap between the frequency spectrum of the cardiac sounds and the human range of audition. Any factor that interferes with this perception process is detrimental. A common interference during any listening task is the background noise that competes with the desired signal. Depending on the type and intensity of a noise and the signal, the noise creates an adverse listening environment by exerting a masking effect on the signal (Newby and Popelka, 1985). In other words, the signal becomes less audible and eventually inaudible within the background noise. The effective masking level (EML) is the detection level at which the acoustic signal has just become inaudible 
within a measured level of noise. Any amount of masking would seem to be detrimental to the cardiac auscultation process because the noise may interfere with the perception of critical elements of the heart sound. At present, the intensities of the EMLs created by different types of noises during cardiac auscultation are unknown. Further investigation of the specific effects of noise on cardiac auscultation are warranted due to the life threatening circumstances and the general lack of knowledge in this area.

Presently, stethoscopes are widely used in the medical professions to monitor the sounds of internal organs of patients in order to differentiate normal from abnormal functions. The stethoscope was invented to augment sound reception and facilitate the fundamental auscultation process. The "direct" or "immediate auscultation" process was previously accomplished by the applying the examiner's ear directly to the patient's body (Chang, 1987). After the initial innovation and subsequent modifications of the stethoscope, there remain two basic types of stethoscopes used in the monitoring of bodily sounds, namely the acoustic stethoscope and the amplified stethoscope. The former has received the most attention in research studies because it was invented earlier and it is the most widely used (Frederick \& Dodge, 1924). To this date, there are no 
calibration standards or specifications for the acoustic properties of the entire stethoscope.

The acoustics delivered via a stethoscope have been assessed both qualitatively and quantitatively by implementing subjective and objective measures. The subjective and objective evaluations have primarily assessed the frequency and intensity characteristics of the functional output of the stethoscope in experimental sound treated environments (Ertel, Lawrence, Brown \& stern, $1966 \mathrm{a}, \mathrm{b}$; Frederick \& Dodge, 1924; Kindig, Beeson, Campbell, Andries \& Tavel, 1982; Mckusick, 1958; Rappaport \& Sprague, 1941). The output of the stethoscope in sound pressure level (SPL) is defined as the intensity provided by the stethoscope during typical user conditions. In the case of an acoustic stethoscope, the functional output is equivalent to it's maximum output, since this device represents a passive system with fixed amplification. Amplified stethoscopes, on the other hand, permit intensity adjustments to be made in accordance with the listener's most comfortable listening level (MCL). The functional outputs on these active systems are represented by intensities measured at the MCL of the listener.

Stethoscopic research has also evaluated the influences of external factors, such as background noise, on the auscultation process (Groom, 1956, 1964). It is inevitable that some degree of noige is delivered along with 
the body sounds to the listener's ear via a stethoscope. The primary component of noise in a stethoscope is the leakage of ambient noise into the stethoscope proper due to the coupling arrangement. The leakage of noise can occur between the skin and the chest piece, the chest piece and the tubing, the tubing and the ear tips, and above all, the ear tips and the ear canals (Groom \& Chapman, 1959; Rappaport \& Sprague, 1952). A second noise component, distortion, is produced by the internal noise of the amplifying structures of the stethoscope.

studies evaluating the influence of background noise tend to employ artificial noise in an attempt to control the unique and variable nature of ambient noise (Groom, 1956 , 1964). Two commonly used types of artificial noise are white noise and cafeteria noise. The former is the most universally used type of noise in research (Miller, 1985). As defined by Yost and Nielsen (1985) "white noise is a noise for which the spectrum density is substantially independent of frequency over a specified frequency range." This frequency spectrum focuses on the human range of audition that approximates 20 to 20,000 Hertz (Hz). In contrast, cafeteria noise is essentially a tape recording of the environmental noise within a cafeteria. The calibrated cafeteria noise tape is derived from a spliced time segment of a comprehensive tape recording. Intensity fluctuations within the time segment are qualified within a decibel range 
centered around the designated intensity level. The time segment is then recorded on a continuous tape loop to generate a controlled source of cafeteria noise. As related to a medical facility, white noise is similar to the hum generated by equipment, and cafeteria noise is comparable to commotion and vocal noise created by people interacting within their environment.

Background noise is measured in decibels with reference to a frequency weighting scale network. The three scales include $d B A$, $d B B$, and $d B C$ in SPL (Figure 1). These scales are designed to approximate human auditory responses to pure tones (Melnick, 1985). The equal-loudness level unit, the phon, denotes a $1000 \mathrm{~Hz}$ referent in dB SPL for loudness comparisons between frequencies. The A-weighted scale approximates human responsiveness for intensity levels below 55 dB SPI (Melnick, 1985), and it represents the most severe low frequency filtering of white noise below $500 \mathrm{~Hz}$ by a contour of 40 phons (Miller, 1985 ; Peterson \& Gross, 1967; Sheeley, 1978). The B-weighted scale approximates intensities between 55 to $85 \mathrm{~dB}$ SPL, and it moderately filters white noise below $200 \mathrm{~Hz}$ by a contour of 70 phons (Melnick, 1985). The c-weighted scale corresponds to intensities above $85 \mathrm{~dB}$ SPL, and it minimally filters white noise below $50 \mathrm{~Hz}$ with a contour of 100 phons (Melnick, 1985). These scales provide a reference for estimating the effect of noise on the human auditory system. 


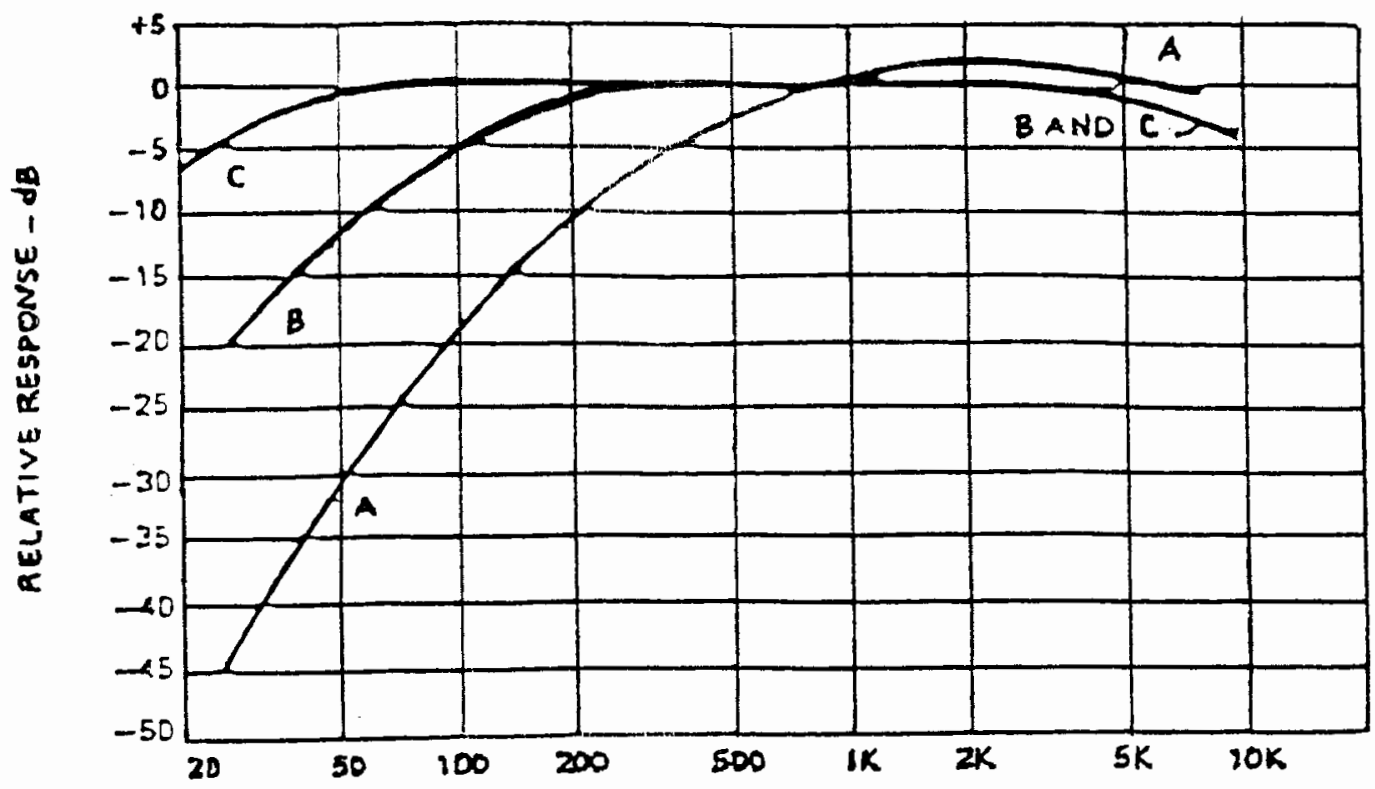

FREQUENCY $-\mathrm{HZ}$

Figure 1. Three weighting scale networks. The scales $d B A, d B B$ and $d B C$ have standardized frequency (Hz) and intensity ( $d B$ SPL) functions used for sound measurement references. Derived from Council for Accreditation in occupational Hearing conservation ( $p .107$ ) edited by $M$. H. Miller, 1985, New Jersey: Association Management Corporation. Copyright 1985 by CAOHC. Adapted by permission. 
Studies investigating the effects of noise usually involve the use of human subjects that are instructed to perform a psychophysical identification or discrimination task. The method of adjustment, is a common task employed for the detection of threshold levels. This method allows the subject to control the parameters of a variable stimulus and compare it to another stimulus that remains constant (Yost \& Nielsen, 1985). This method was implemented in the study by Groom (1956) to establish a threshold of audibility during auscultation. The listener adjusted the volume of the heart sound until he could just audibly detect the heart sound in quiet, and later, in ambient noise (Groom, 1956). The few studies that have researched the influence of background noise during ausultation have agreed that background noise levels can have an adverse masking effect on the cardiac signal (Groom, 1956, 1964). The degree of detriment is dependent on several internal and external factors involving the listener (hearing acuity and expertise), the signal (the different intensity and frequency ranges), the stethoscope (the type and coupling arrangement), and the environment (the type and intensity of the background noise). All of these variables limit the use reliability of the stethoscope in a medical setting where auscultatory monitoring is imperative to diagnostic decisions. 
The lack of implementatory standards regarding the acoustic output of stethoscopes and the masking effects of noise have a direct impact on the auscultation process. The primary function and use of the stethoscope is to enhance normal or aberrant cardiac sounds during a preliminary diagnosis or while monitoring a pre-existing condition. In both circumstances, the sooner the aberrant heart condition is detected, the better the treatment prognosis. Thus, further investigation is warranted to disclose the relationship between background noise and cardiac auscultation.

The primary purpose of this study was to evaluate the interference created by competing background noises during cardiac auscultation. In an attempt to control the multiple variables and achieve some correspondence with real life medical settings, two types or noise environments were selected, white noise and cafeteria noise. Both noises were recorded in the dBA scale for direct comparison with background noise studies of medical setting. These two noise environments were selected because they both provided a constant noise source with controlled fluctuations. In particular, white noise has a standardized uniform spectrum of energy that encompasses all frequencies within the range equally, and therefore the noise is easily replicated for the present and future gtudies. Cafeteria noise was selected because it provides a more realistic noise source. 
However, it is less standardized and future replication may be more variable. The primary objective was accomplished by determining the intensity of the EMLs for equal intensities of white noise and cafeteria noise during cardiac auscultation.

secondary objectives of the study intended to evaluate any potential differences between the two types of stethoscopes, and between the effects of the two noise environments. Depending on the results, it might prove advantageous to select a type of stethoscope based on the listening environment in which it is to be used. In addition, information about the subjective and objective effects of the both noises may provide a basis for reducing their potential effect. The secondary objectives were accomplished by evaluating the following: 1. An examination of the potential difference of noise masking levels between an acoustic stethoscope and an amplified stethoscope. 2. An examination of the potential difference between the effective masking level of the white noise and the cafeteria noise. 3. An investigation of the listener's subjective judgments regarding stethoscope performance in quiet, white noise and cafeteria noise. 
CHAPTER II

\section{REVIEW OF THE LITERATURE}

Dr. R.T.H. Laennec in 1816 was the first to document the use of an apparatus to improve the auscultation procedure during cardiac screening (sakula, 1981). Laennec's discovery was initially the use of several pieces of paper rolled into a tube. This discovery inspired his development of a hollow, wooden cylinder with a flared funnel base. He named his invention the stethoscope, which is a combination of two Greek words meaning chest and to inspect.

Since the stethoscope's first public introduction in 1819, it has functioned to conduct internal body sounds at the surface of the skin to the examiner's ears. Every structural component along this conduction process inherently changes the acoustic transmission of the sound. As a result, many structural modifications and studies of the instrument have been made over the years to improve sound transmission. Eventually from these modification studies evolved the two primary styles of stethoscopes that are in use today; the acoustic stethoscope and the amplified stethoscope. 


\section{ACOUSTIC STETHOSCOPE}

The acoustic stethoscope is constructed of three basic parts, the chest piece, the tubing and the ear tip. The chest piece is in direct contact with the patient's skin, and it funnels sound to the tubing. There are two chest piece designs; the bell or Ford chest piece, and the diaphragm or Bowles chest piece (Littmann, 1972). Acoustically, the bell chest piece transmits less distortion and it has a lower frequency response range then the diaphragm chest piece (Littmann, 1972). Contrarily, the diaphragm design has a greater diameter which enables it to receive more stimulation then the bell chest piece, and the diaphragm itself acts as a high-pass frequency filter (Fredrick \& Dodge, 1924; Littmann, 1972). According to Kindig, et al. (1982) the two chest pieces differ in functional output by approximately 2 dB SPL.

The tubing portion of the stethoscope conducts the sound from the chest piece to the ear tip. There are two variations of the tubing that affect the sound transmission. The first variation includes a monaural or binaural tubing design which acoustically influences the frequency and intensity characteristics of the transmitted sound. Objective measures demonstrate that a monaural stethoscope has a predominant frequency range enhanced by 5 dB SPL between 850 to $1000 \mathrm{~Hz}$, while a binaural stethoscopic design 
has a $20 \mathrm{~dB}$ SPL enhancement between 60 and $400 \mathrm{~Hz}$ (Rappaport \& sprague, 1941). Subjective comparisons, on the other hand, show no significant qualitative, e.g., clarity and intelligibility of sound, or quantitative, e.g., improved amplification, preference between the monaural and binaural fittings (Kindig, et al., 1982). Thus, the tubing design has a negligible affect on the acoustical properties for the listener.

The second variation pertains to the tubing length from yoke to chest piece. Studies investigating the affects of tubing length on stimulus output have shown that stethoscopes function more efficiently, in that they provide more amplification and less pitch variation, with shorter tubing length (Groom, 1964; Littmann, 1972 ; Rappaport \& sprague, 1941). However, according to Littmann, 1972, the difference created by the length of the tubing is significant only between the extreme measurements that range from 6 to 36 inches. Since the former length is too short and the latter is too long for most purposes, a length of 20 inches has been arbitrarily accepted, as stated by Groom (1964) as a "practical compromise."

The ear tip of the stethoscope fits into the outer portion of the ear canal to deliver the sound waves directly to the peripheral auditory system. The size of the ear tip and it's fit affect the amount of sound leakage into and out of the canal. Depending on the tubing design, monaural or 
binaural, there are either one or two ear tips. Two ear tips provide a bilateral occlusion effect which reduces the listener's task of inhibiting environmental noises.

The amplification spectrum of an intact stethoscope as derived from pure tone stimuli reveal near threshold intensity values with prominent frequency peaks from 125 to $800 \mathrm{~Hz}$ (Ertel, et al., 1966a,b; Fredrick \& Dodge, 1924; Johnston \& Kline, 1940; Kindig, et al., 1982). Complex stimuli of normal taped and live heartbeats reveal lower peaks from 50 to $125 \mathrm{~Hz}$ at approximately 0 to 5 dB SL above threshold (Groom, 1956, 1964; Kindig, et al., 1982; Oliver, 1989). Thus, an acoustic stethoscope innately enhances the low frequency characteristics of the auscultated stimuli.

\section{AMPLIFIED STETHOSCOPE}

In the early 1900's, an "electrical" or amplified stethoscope was designed not for it's clinical application, but for the educational ear-training of medical interns (Fredrick \& Dodge, 1924; Gamble \& Repologle, 1924; Rappaport \& Sprague, 1941). Today, the amplified stethoscope is in use clinically. The amplified stethoscope is an acoustic stethoscope with hearing aid circuitry. In addition to the three basic parts, the chest piece, tubing and ear tip; it consists of a microphone, an amplifier, a receiver, a power source and a volume control like a hearing aid. Basically, the amplification process includes the following steps. The 
microphone receives and converts the acoustic energy of the sound into an electrical energy charge. The amplifier receives and amplifies the electrical charge. The receiver transduces the amplified electrical charge into acoustic energy, and conducts the amplified sound into the tubing. The fourth and fifth components, the power source and volume control, provide the energy supply and allow variable attenuation of the amplified output respectively.

In reference to the amplification delivered via an amplified stethoscope, several manufacturer's specifications report that the amplifier, not the intact instrument, can supply 30 to 40 dB SPL signal gain at frequencies above 100 Hz (Oliver, 1989). No specifications included the intensities levels below $100 \mathrm{~Hz}$.

In the study by oliver (1989), the frequency and intensity spectrums of two amplified stethoscopes were compared with an acoustic stethoscope in audiometric quiet using real ear measurements. The frequency range of the two amplified stethoscopes were found to basically parallel the acoustic stethoscope's response to complex cardiovascular sounds. The total range of frequencies ranged from 50 to $800 \mathrm{~Hz}$ with the primary resonant peak for all three stethoscopes at $50 \mathrm{~Hz}$. The intensity range for the two amplified stethoscopes reflected frequency responses at 50 Hz ranging from -4 to 3 dB SPL to 19 dB SPL at varying peaks above $50 \mathrm{~Hz}$ relative to the acoustic stethoscope results 
(Figure 2). Overall, both amplified stethoscopes were found to provide more gain above $50 \mathrm{~Hz}$ in quiet then the acoustic stethoscope.

\section{STETHOSCOPIC RESEARCH}

Research has attempted to qualitatively and quantitatively evaluate the functional output of the stethoscope since it's invention in the early $1800^{\prime} s$. Thus far, there is no consensus on a standardized calibration procedure, and there are no acoustic specifications required for manufacturing a stethoscope.

Qualitative research on the functional output of the stethoscope has utilized biologic listening tasks performed by inexperienced and trained expert auscultators. Psychoacoustic methodology has been used to evaluate various subjective discriminatory parameters, e.g., clarity, pitch and loudness, of the intact stethoscope. The subjective nature of these personal preference evaluation techniques demonstrated high variability with poor standardization capabilities. However, trends are noted and generalized with caution.

Quantitative research of the functional output of the stethoscope has consisted of two different methods, an electroacoustical evaluation and real ear measurements. The electroacoustic methodology is similar to the electroacoustical evaluation of hearing aids. This method 


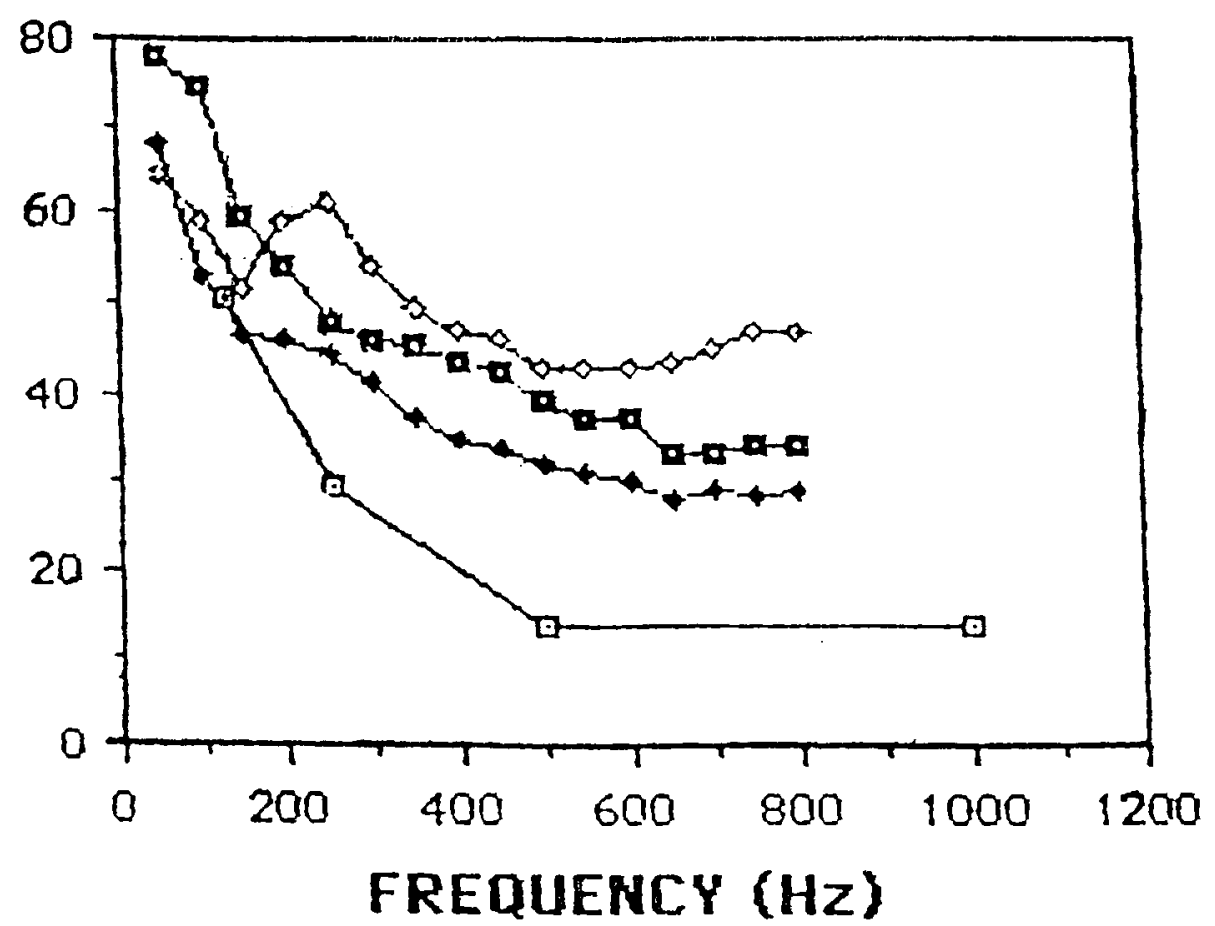

Fiqure 2. Mean output of three stethoscopes. The output of the acoustic sprague-Rappaport LAB 600 [ $\leadsto$ ], the amplified Bosch EST 40 [ $\square$ ] and the amplified starkey $S T 3$ [ $\diamond$ ] are in $d B$ SPL as a function of frequency. Input to the stethoscopes was normal heart sounds. Output was measured by a probe tube system in the subject's ears. The lower curve [ $\square$ ] represent the mean threshold of audibility for the subjects. From "In situ Measurements of Two Amplified and one Acoustic stethoscope" by $S$. R. A. Oliver, 1989, (Masters dissertation), p. 30 . Reprinted by permission. 
can monitor the intact stethoscope, but it is typically used to evaluate the individual structural components of the stethoscope separately, e.g. amplifier, chest piece, and tubing. In general, the schematics incorporated the elicitation of a pure tone stimulus which was directed through the component to a receiver for analysis. The objective nature of this technique lends itself to better standardization than the qualitative research. However, the pure tone stimulation is not representative of the complex nature of body sounds.

Real ear measurement instrumentation allows a direct acoustic evaluation of sound delivered to the listener's ear canal. Although the customary use of real ear measurements is to evaluate hearing aid responses in situ, its application to the amplification via a stethoscope provides an evaluation of body sounds in the ear canal of the stethoscope user. This measurement provides a frequency/intensity function analysis of complex sounds during actual auscultation. This method of measurement was implemented by oliver (1989) to evaluate the frequency and intensity responses of a stethoscope in quiet.

\section{HUMAN HEARING}

The human sensitivity curve for audition is stimulus dependent on intensity as a function of frequency (Figure 3). Threshold levels are represented by one of the 


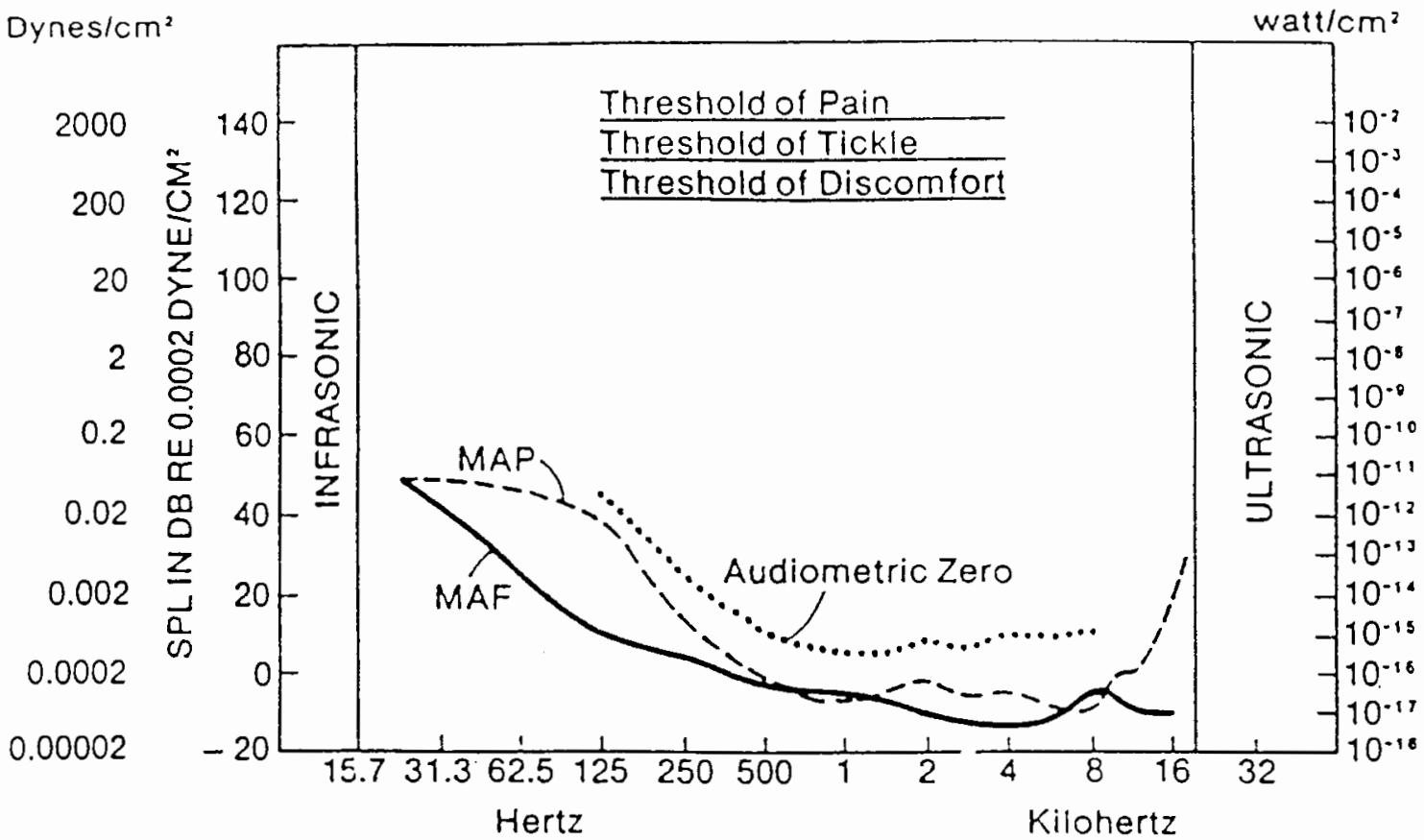

\section{FREQUENCY}

Fiqure 3 . Human dynamic range of audition.

Represented here are three threshold and three suprathreshold curves. Threshold results were obtained in soundfield for the minimum audible field (MAF - solid line), under earphones for the minimum audible pressure (MAP - dashed line), and standardized by ANSI (1969) in the audiometric zero curve (dotted line).

Suprathreshold curves of discomfort, tickle and pain are maximum sensation levels. Derived from Audiology, 5 th Edition (p. 17) by H. A. Newby and G. R. Popelka, 1985, New Jersey: Prentice Hall Inc. Copyright 1985 by Prentice Hall Inc. Adapted by permission. 
three customary measurements, minimum audible field (MAF), minimum audible pressure (MAP) or audiometric zero. The MAF measurements obtained in sound field and the MAP measurements acquired via ear phones most accurately reflect the average young adult auditory sensitivity in ideal testing conditions. These measurements attempt to encompass the broad range of human frequency reception that spans from 20 to $20,000 \mathrm{~Hz}$. The ANSI 1969 standards have adapted a more conservative audiometric zero curve to provide a standardized reference for audiometric evaluations within the speech frequency from 100 to $8000 \mathrm{~Hz}$. Below $100 \mathrm{~Hz}$, audiometric calibration is not standardized, and most audiometers have a low frequency cut off at 125 or $250 \mathrm{~Hz}$. This lack of standardization limits human auditory threshold comparisons with sounds that generate their primary frequency and intensity peaks below $100 \mathrm{~Hz}$, such as heart sounds.

Humans also have a large dynamic range of intensity reception. The evaluation of this receptive intensity range begins with the detection threshold of sound, approximately audiometric zero in dB HL, and terminates near the threshold of pain, approximated at $140 \mathrm{~dB}$ SPL (Figure 3). Prior to the threshold of pain, there are two other sensation levels, the threshold of discomfort and the threshold of tickle. At these supra-threshold levels, human auditory perception is relatively equivalent for the frequency-intensity functions. 
on the other hand, threshold and near threshold values are very dependent on the frequency-intensity function that allows human audition. Such that, the human auditory system is the most insensitive to levels that occur specifically in the lower frequency range below $500 \mathrm{~Hz}$ where more sound pressure is needed to elicit a threshold value for normal hearing listeners.

\section{HEART SOUNDS}

In terms of human perception, heartbeats created by muscle contractions are very faint. Their perception approximates the normal human threshold of detection (Groom, 1956, 1964; Williams \& Dodge, 1926). According to Williams and Dodge (1926) cardiovascular sounds have a limited low frequency range between 5 and $660 \mathrm{~Hz}$, and a primary resonant peak around 50 to $60 \mathrm{~Hz}$. The average MAF threshold of audibility at $50 \mathrm{~Hz}$ is $43 \mathrm{~dB}$ SPL (Newby \& Popelka, 1985), while the real ear intensity of heartbeats at that frequency ranges from 63 to 79 dB SPL depending on stethoscope type (Oliver, 1989). Thus, the functional overlap between heartbeat perception and human audition at $50 \mathrm{~Hz}$ has an average intensity sensation level (SL) of 20 to 36 dB SL. In the 1989 study by oliver, the functional overlap ranged from 0 to $20 \mathrm{~dB}$ SL for an acoustic stethoscope and 0 to 40 dB SI for an amplified stethoscope across the test frequency range of 50 to $800 \mathrm{~Hz}$ (Figure 2). Consequently, the primary 
sounds of the heartbeat, in relation to the threshold curve at the same frequency region, are located in the least sensitive frequency region of human audition.

\section{BACKGROUND NOISE}

Background noise is a type of noise that is generated by a specific environment, a generally unwanted sound that is usually complex and aperiodic in nature. As defined by Sheeley (1978) masking noise is "..a signal that interferes with the detection or discrimination of another signal." In general, as the noise level increases, the ability to discriminate acoustic stimuli decreases until a maximum saturation level is reached. The beginning point of this saturation level is referred to as the effective masking level (EML) during audiometric test procedures. specifically, the EML refers to the intensity level of the noise when it "just masks" the intensity level of the signal, and the signal becomes less audible (sheeley, 1978). The unpredictable nature of ambient noise makes it difficult to measure. The general characteristic state of noise has two broad descriptive categories: steady state noise which is relatively continuous, and impulse noise which is instantaneous. Extraneous noise is typically a combination of both steady state and impulse noises. In order to classify these two entities, noise levels are represented by their median dB SPL of a referent weighting 
scale, the frequency band width, and the intensity range. The median $d B$ SPL and the intensity range is derived from sound level meter readings, while frequency fluctuations are graphically recorded on a frequency analyzer. The high points and low points of the intensity and frequency fluctuations are noted throughout the frequency analyzer recording, and a time weighted average of the noise source is calculated for the designated period of time at that specific location.

\section{CLINICAL BACKGROUND NOISE}

Clinical background noise refers to the noise level within a particular clinical setting, and like most noises, it is comprised of a variety of complex steady state and impulse sounds of several intensity levels. The Environmental Protection Agency (EPA, 1974) and the World Health Organization (WHO, 1980) have recommended that ambient noise levels within hospital settings be at or below 35 dBA at night and 40 dBA during the day time (Hilton, 1985). These guidelines were suggested in order to provide an environment that is conducive for both monitoring patients and their recovery.

The effects of noise interference are both physiological and psychological. Several studies have investigated the relationship between hospital noise and subtle changes within the cardiovascular, endocrine and the 
auditory systems, as well as increases in stress, sleeplessness, fatigue and the perception of pain (Falk \& Woods, 1973; Hilton, 1985, 1987; Shapiro \& Berland, 1972; Turner, King \& Craddock, 1975; Woods \& Falk, 1974). Patients in particular are more susceptible to the effects of noise than healthy people because they have reduced tolerance levels for sounds (Harris, 1979; Lipscomb, 1974). In addition to noise levels increasing patient discomfort, noise also degrades speech communication and any form of acoustic monitoring, such as cardiac screening.

The majority of the research involving hospital ambient noise levels tend to concentrate on the intensive or acute care units, and the patient recovery rooms (Falk \& Woods, 1973; Hilton, 1985, 1987; Shapiro \& Berland, 1972; Turner, et al., 1975; Woods \& Falk, 1974). The results from several of these surveys, involving various hospital environments, reveal dBA SPL meang and ranges that predominately exceed the EPA and wHo recommendations of 35 to $40 \mathrm{dBA}$ ( $\mathrm{Table} I$ ). Noise awareness and reduction should become common practice in all hospital settings according to these recommendations.

\section{BACKGROUND NOISE AND AUSCULTATION}

The adverse effects of background noise on the auscultation procesg has been invegtigated in studies by Groom, (1956, 1964). In the first study, the intensity of 
TABLE I

SURVEY OF HOSPITAL BACKGROUND NOISE

LOCATION

dBA $\bar{x}$

dBA RANGE

REFERENCE

INTENSIVE (ACUTE) CARE UNITS

$I C U$

$+50$

ICU small hospital

ICU large hospital

$A C U$

$A C U$

Medical-surgical ICU

Coronary ICU

$+65$

$-60$

Hilton 87

Hilton 85

Hilton 85

Woods 74

Falk 73

Turner 75

Turner 75

RECOVERY ROOMS

$R R$

$\mathrm{RR}$

$\begin{array}{ll}45 & -84 \\ 45 & -84\end{array}$

woods 74

Open-heart $R R$

$+50$

$34.25-62.5$

$50-76$

$50-70$

$-50$

Falk 73

Pre-operative RR

$-50$

Hilton 87

Hilton 87

Post-operative RR

Hilton 87

OPERATING ROOM

$55-86$

Shapiro 72

Note: A summary of hospital background noise level surveys recorded in various locations with findings reported in mean dBA or an average low to high dBA range. 
tape-recorded heart sounds transmitted through an

"artificial precordium" was adjusted to the threshold of audibility by experienced listeners in audiometric quiet and in $65 \mathrm{~dB}$ of taped "artificial background noise". The listener-adjusted stimulus intensity was greater for the noisy environment. The second study by Groom (1964) evaluated the efficiency of 33 stethoscopes in audiometric quiet and in $65 \mathrm{~dB}$ of white noise. Using the same procedures as above, "..the threshold of stethoscopic audibility" was measured. The results revealed poorer thresholds of stimulus audibility for the noisy environment. In summary, the two basic types of stethoscopes, the acoustic stethoscope and the amplified stethoscope, both conduct an augmented signal to the ligtener's ears. However, the audition of the conducted sound is dependent upon the detection and discrimination of the characteristic frequencies and intensities of the stimulus by the listener. The frequency and intensity ranges characteristic of heartbeat sounds are detectable at the lower and most inefficient region for human audition. This fragile link of detection is further deteriorated by the masking potential of background noise. Studies evaluating the noise levels in several medical facilities have reported excessive levels of noise in most locations. There are few studies available that have specifically evaluated the adverse effects of noise on cardiac screening via a stethoscope. consequently, 
the effects of noise on cardiac auscultation deserve further investigation.

The present study is different from the previous studies investigating the effects of noise on cardiac auscultation in that: 1. The human heart sound used for the stimulus was "live" rather than a tape recording transmitted through a manufactured precordium as seen in Groom's studies $(1956,1964)$. 2. The experimental noise levels were varied instead of being pre-set at a constant level. 3. Inexperienced listeners were used in place of experienced cardiac auscultators. 4. Only two stethoscopes, one acoustic and one amplified, were used throughout the experiment. The previous procedural differences were aimed at providing new information regarding stethoscopic function during cardiac auscultation in competing background noise.

\section{STATEMENT OF THE PROBLEM}

This study primarily evaluated the sound pressure levels of competing background noises, white noise and cafeteria noise, that effectively masked heart sounds during cardiac auscultation. The primary hypothesis stated that there would be a relatively low, e.g., 65 to 75 dBA, EML of both white noise and cafeteria noise that adversely effects cardiac auscultation. This hypothesis was based on the assumption that the competing background noises used within 
the study were relatively representative of the average noise ambience within most hospital settings. If the data supported the primary hypothesis, then most hospital settings that were reported earlier provide an adverse listening condition for cardiac auscultation, and appropriate measures should be taken to improve the $\mathrm{s} / \mathrm{N}$ within the environment and/or the stethoscopic instrument employed. If the data do not reflect this hypothesis, then most hospital settings appear to provide an adequate environment for cardiac ausculation, at least for normal hearers.

This study addressed the following questions: 1 . At what sound pressure level does white noise mask cardiac sounds during auscultation? 2. At what sound pressure level does cafeteria noise mask cardiac sounds during auscultation? 3. Is there a significant difference in effective masking levels (EML) between white noise and cafeteria noise during cardiac auscultation?

4. Is there a significant difference in EML levels during auscultation through an acoustic stethoscope and an amplified stethoscope set at MCL? 5. Is there a significant difference between the subjective performance judgments of the two stethoscopes, the acoustic stethoscope and the amplified stethoscope, during cardiac auscultation in quiet and in noise? 
CHAPTER III

\section{METHODS}

The foregoing review of the literature suggested that competing background noise provides an adverse listening environment for cardiac auscultation. In the present study, the relationship between two noise types, white noise and cafeteria noise, and the audibility of the heart sounds through two stethoscopes, an acoustic stethoscope and an amplified stethoscope, was quantified and qualified respectively by objective and subjective measures. objective measurements involved an effective masking level (EML) identification task; and subjective results were answers to a written questionnaire. An analysis and comparison of the data from both measures were used to address the experimental questions.

\section{SUBJECTS}

The stethoscope listeners consisted of 16 females with normal hearing, who ranged from 16 to 38 years of age. Normal hearing was defined bilaterally as $15 \mathrm{~dB}$ HL or lower at the ANSI test frequencies from 125 to $4000 \mathrm{~Hz}$ (Figure 4). The measurement of auditory thresholds below $125 \mathrm{~Hz}$ was not possible due to the output limitations of the audiometer. 
$\begin{array}{llllllllll}\text { A } & \text { U } & \text { D } & \text { I } & \text { O } & \text { G } & \text { R } & \text { A } & \text { M }\end{array}$

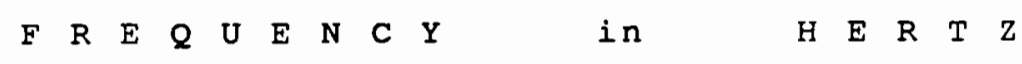

\begin{tabular}{rrrrr}
125 & 250 & 500 & $1000 \quad 2000$ & 4000 \\
\hline
\end{tabular}

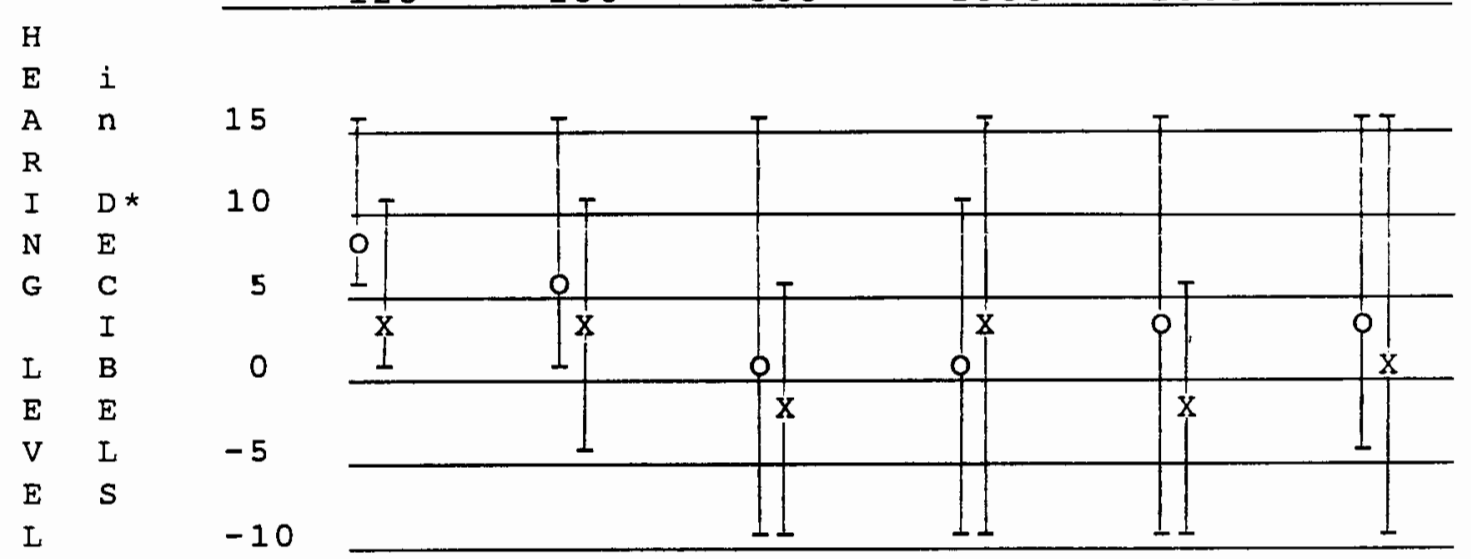

* dB reference is to .0002 dynes/cm ${ }^{2}$.

Eigure 4. Listener's mean thresholds of audibility. The audiogram digplays the threshold means for the listener's right ears [O] and left ears [X] across the test frequency range of 125 to $4000 \mathrm{~Hz}$. The vertical lines represent the threshold response range. 
It was assumed that the 1 isteners had normal auditory thresholds below $125 \mathrm{~Hz}$ if they passed the above screening criteria. The experienced auscultator also exhibited normal hearing sensitivity as previously defined. An adult healthy male assistant, age 40, was pre-examined by an experienced medical cardiac auscultator and later provided the normal heartbeat signal in the experiment.

\section{INSTRUMENTATION}

The experimental protocol required an acoustic stethoscope, amplified stethoscope, pure tone audiometer, variable attenuator, phase linear amplifier, tape recorder, sound level meter, volt meter and a sound field chamber. The sprague-Rappaport LAB 600 acougtic stethoscope and the BOsch EST 40 amplified stethoscope were the stethoscopes evaluated. Both stethoscopes provided a constant volume presentation. The adjustable volume control on the amplified stethoscope was at a fixed setting throughout the experiment. This volume was set by the experienced auscultator at her most comfortable listening level for the heart sound in audiometric quiet.

The white noise source used in sound field testing was generated by a Beltone 2000 clinical audiometer through a Leader LAT-45 attenuator which was controlled by the subject by means of an attenuator dial (Figure 5). Output of the attenuator was fed to a crown D-75 amplifier. The output of 


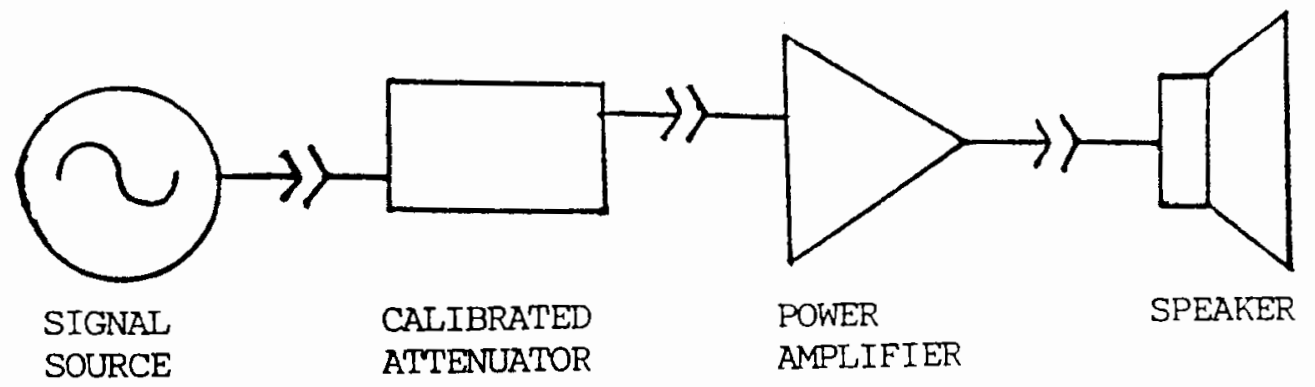

Figure 5. Schematic representation of equipment. The noise was elicited at the audiometer, adjusted at the attenuator, a umented at the amplifier and finally presented via the loud speaker into the acoustic chamber. Wiring connections through the chamber wall are designated by the $[\rightarrow>$ ] symbol. 
inches from vertex to the loudspeaker, and at 180 degree azimuth (Figure 6). At this fixed sitting position from the loudspeaker, a constant field of noise was measured with the sound level meter, and no difference was noted in the dB SPL readings at either ear or the vertex of the model's head. The assistant was seated off to the right side of the Iistener, and out of the direct line of the speaker. Based on the sound level meter readings, this arrangement provided a constant $\mathrm{s} / \mathrm{N}$ for each subject, and eliminated any body baffle or sound reflection effect by the assistant.

The assistant's chest was marked for consistent chest piece location throughout the experiment. The mark was situated at the apical position of the heart. The chest piece of the stethoscope was aligned and hand held by the assistant on his chest at the designated mark with appropriate pressure applied in accordance with clinical recommendations from the experienced auscultator.

Each listener read the following written instructions that explained the experimental task:

1. Familiarize yourself with the heart beat sound in quiet by listening to it for a few minutes. Listen for both beats of the heart, e.g., the "lub-dub."

2. When you are ready, this control box dial allows you to either increase or decrease the noise level from the loudspeaker.

3. Your purpose during the first few trials is to increase the noise level by turning the dial clock-wise until the heart sound is inaudible, and then raise your hand. 


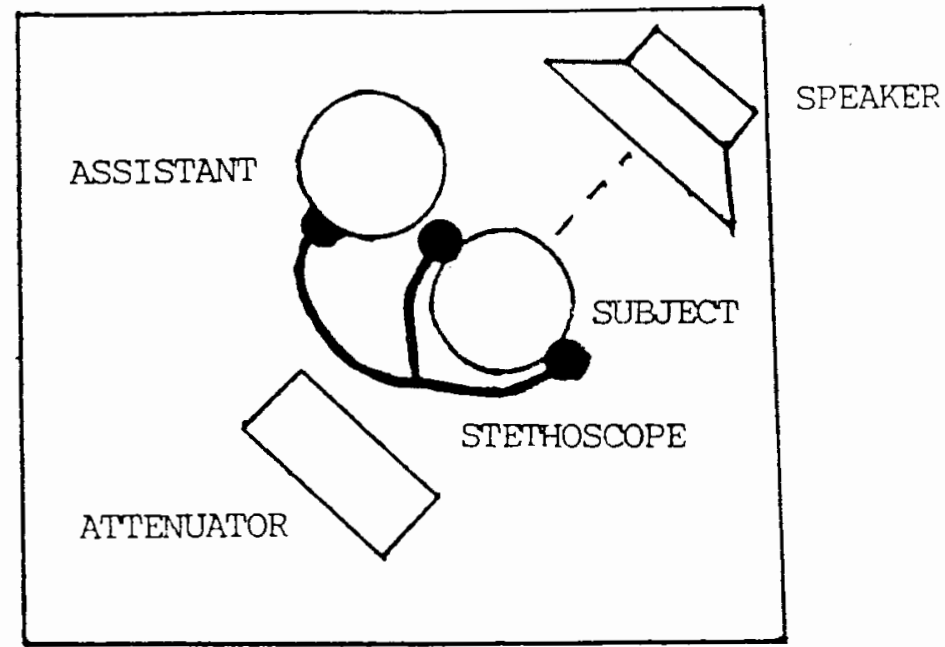

Figure 6. Overhead view of experimental arrangement. The subject, assistant and equipment were arranged within an acoustic chamber. The dashed line represents a measured distance of 21 and one-forth inches between the subject's vertex and the loud speaker. This distance provided a constant field of noise presentation to both ears. 
4. Your purpose during the second few trials is to decrease the noise by turning the dial counter-clock-wise until the heart sound is just audible, and then raise your hand. Do not increase and decrease the noise in the same trial.

5. During each trial, look straight ahead at the designated point on the wall.

6. Do you have any questions about the instructions?

The listener's task was to adjust the level of the noise to a value which just masked the cardiac sound. This level was termed the "effective masking level" or EML. Stated differently, the EML occurred when the listener signaled that the cardiovascular sounds were completely masked by the noise. The EML was determined by means of the method of adjustment. The detection identification task incorporated ascending and descending trials in the two different ambient noises. The attenuator dial allowed the listener to increase or decrease either noise level in increments of one dB HL. During an ascending trial, the listener increased the noise level until the heart sounds became inaudible. On the descending trial, the listener decreased the noise level until the heart sounds were just audibly detected. The purpose of these two trial methods, ascending and descending, was to establigh an unbiased mean effective masking level of the heart sounds for each stethoscope in both of the noise environmenta. 


\section{DATA MEASUREMENT AND ANALYSIS}

The order of the two stethoscopes, the two noise environments, and the ascending and descending trials were counterbalanced to avoid any order bias. To reduce the possibility of any association bias with the stethoscopic names, the acoustic stethoscope and the amplified stethoscope were respectively labeled as stethoscope "A" and "B". Each stethoscope was evaluated in the two noise environments by recording both the attenuation value from the attenuator dial and the audiometer setting for four ascending and four descending trials. Prior to each trial, the audiometer setting was selected in accordance with a random numbers table (Mendenhall, 1979). The calculated dB SPL of the noise in sound field was derived from the three recorded values on the attenuator, the audiometer, and the calibrated sound level meter readings. The initial trial of each ascending and descending identification task was used for task familiarization only. The remaining three trials were used to establish mean effective masking levels, 95 percent confidence intervals, and to check the intra-rater reliability.

subjective and qualitative data were obtained through the administration of a scaled forced-choice questionnaire. The listener's judgments of stethoscopic performance pertained to the comfort of the loudness listening level, 
the quality and clearness of sound, the goodness of ear tip fit, the effectiveness of ear tip noise attenuation, and her overall impression of the instrument (Appendix 1). The listener ranked each stethoscope on a five point scale from very poor to excellent in the three listening environments: quiet, white noise and cafeteria noise. The questionnaire was initially read by the listener and clarified by the experimenter along with the written instructions. It was then filled out after the completion of each stethoscopic analysis. The data provided arithmetic means for statistical analysis. 


\section{RESULTS AND DISCUSSION}

This two-part study examined the objective and subjective effects of background noise during cardiac auscultation. Two stethoscopes, an acoustic stethoscope and an amplified stethoscope, were evaluated in two noise environments, white noise and cafeteria noise, through an effective masking level (EML) detection identification task and a qualitative questionnaire. Data from both the objective and subjective measures were used to address the experimental questions.

\section{RESULTS}

The EML means and standard deviations in dBA of the combined ascending and descending methods for each stethoscope within both noise environments are as seen in Table II. The mean EMLs and the 95 percent confidence intervals for each objective trial series are seen in Figure 7. The significance of these data were analyzed using a Multivariate Analysis of Variance (MANOVA) with an alpha level of .05. Relationships were computed for main effects, first order interactions and second order interactions between the two stethoscopes, the two noise environments and 
TABLE II

MEAN ABA DATA COMPARISON FOR STETHOSCOPES AND NOISE

ACOUSTIC STETHOSCOPE

AMPLIFIED STETHOSCOPE

\section{WHITE NOISE}

$95.6355 \mathrm{dBA}$

(4.7545)

$94.3910 \mathrm{dBA}$

$(4.5960)$
CAFETERIA NOISE $92.1045 \mathrm{dBA}$

(8.7285)

$93.0625 \mathrm{dBA}$

(10.2960)

Note: The effective masking level (EML) means in dBA and standard deviations in parentheses of the combined ascending and descending trials for the acoustic stethoscope and the amplified stethoscope in white noise and cafeteria noise. 
$\begin{array}{lllllllllllll}S & T & E & T & H & O & S & C & O & P & E & S:\end{array}$
A $C$ C

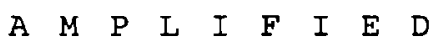

\begin{tabular}{|c|c|c|c|c|}
\hline $\mathrm{dBA}$ & $\begin{array}{l}\text { WHITE } \\
\text { NOISE }\end{array}$ & $\begin{array}{l}\text { CAFETERIA } \\
\text { NOISE }\end{array}$ & $\begin{array}{l}\text { WHITE } \\
\text { NOISE }\end{array}$ & $\begin{array}{r}\text { CAFETERIA } \\
\text { NOISE } \\
\end{array}$ \\
\hline \multicolumn{5}{|c|}{100} \\
\hline 99 & & $T$ & & \\
\hline 98 & & & & \\
\hline 97 & [ & & & \\
\hline 96 & & & & $T$ \\
\hline 95 & & & & \\
\hline 94 & & 0 & & \\
\hline 93 & & $T$ & & ? \\
\hline 92 & & 1 & & $\dot{t}$ \\
\hline 91 & & & & \\
\hline 90 & & 1 & & \\
\hline 89 & & $t$ & & \\
\hline 88 & & & & 1 \\
\hline 87 & & & & \\
\hline 86 & & & & 1 \\
\hline 85 & & & & \\
\hline 84 & & 1 & & \\
\hline 83 & & & & \\
\hline 82 & & & & \\
\hline 81 & & & & \\
\hline 80 & & & & \\
\hline
\end{tabular}

Fiqure 7. Mean effective masking levels for an acoustic stethoscope and an amplified stethoscope in white noise and cafeteria noise. The ascending trial means are represented by an [*] and the descending trial means by a [0]. The vertical lines display the 95 percent confidence intervals. 
the two trial methods. The only significant difference of the $F$ statistic was found between the ascending and descending methods for the identification task with a .049 level of significance. All other values were insignificant at the .05 level as seen in Table II.

Listener intra-reliability was analyzed by using the Pearson Product Moment Coefficient of Correlation (Pearson r) for each trial set (Table IV). The repeated measure correlation was good, greater than.5, for all data with one exception. The condition for the amplified stethoscope in white noise with an ascending identification task for trial comparison $(3-4)$ displayed a low .2225 pearson $r$ correlation.

The questionnaire data were analyzed using a dependent two-tailed T-test analysis. Although the amplified stethoscope received higher performance ratings in all of the listener judgement categories then the acoustic stethoscope (Table V), this trend was not supported by the T-test analysis. As seen in Table VI, all T-score values fell within the table values of -1.96 and 1.96 (Mendenhall, 1979). Thus, all T-scores failed to demonstrate a significant difference between the stethoscope ratings at a 5 percent level of confidence. 


\section{TABLE III}

MULTIVARIATE ANALYSIS OF VARIANCE (MANOVA):

A COMPARISON OF STETHOSCOPES, NOISE AND METHODS

VARIABLES

MAIN EFFECTS

$\begin{array}{ll}\text { Acoustic } & \text { by Amplified } \\ \text { White } & \text { by Cafeteria } \\ \text { Ascent } & \text { by Descent }\end{array}$

FIRST ORDER INTERACTIONS

Stethoscopes by Noises

Noises

Methods
SS

$\begin{array}{rr}1974.01 & 15 \\ 709.63 & 15 \\ 524.38 & 15\end{array}$

$392.69 \quad 15$

$187.64 \quad 15$

by stethoscopes $492.89 \quad 15$
MS

131.60

47.31

.00

3.99

34.96

4.58

.945

.064

$\star .049$

SECOND ORDER INTERACTIONS

Stethoscopes by Noises

by Methods $271.89 \quad 15$ $18.13 \quad 2.14 \quad .164$

* Significant at the 5 percent level.

Note: The MANOVA results reported in sums of squares (SS), Degrees of Freedom (DF), Mean square (MS), the F statistic (F) and the significance of $F$ (sig F), compared various interactions between the stethoscopes (Acoustic and Amplified), the noise environments (White and cafeteria) and the identification task methodology (Methods = Ascent + Descent). 
TABLE IV

PEARSON PRODUCT MOMENT COEFFICIENT OF CORRELATION:

(PEARSON $r$ )

ACOUSTIC STETHOSCOPE

WHITE NOISE TRIAL\# ASCENT DESCENT

$\begin{array}{llll}2-3 & = & .7424 & .9028 \\ 3-4 & = & .8118 & .9142 \\ 4-2 & = & .8186 & .8338 \\ \text { CAFETERIA } & \text { NOISE } & \\ 2-3 & = & .7314 & .8222 \\ 3-4 & =.8697 & .7998 \\ 4-2 & = & .6720 & .8305\end{array}$

AMPLIFIED STETHOSCOPE

PEARSON $r$

WHITE NOISE

TRIAL \#

DESCENT

$\begin{array}{llll}2-3 & = & .5764 & .9529 \\ 3-4 & = & .2225 & .9174 \\ 4-2 & = & .5046 & .9329 \\ \text { CAFETERIA } & \text { NOISE } & \\ 2-3 & = & .8183 & .8764 \\ 3-4 & = & .8335 & .9257 \\ 4-2 & =.7422 & .9322\end{array}$

Note: The Pearson Product Moment Coeffiecient of Correlation (Pearson $r$ ) data collected for listener intrareliability analysis of three trials $(2,3,4)$ while using an acoustic stethoscope and an amplified stethoscope in white noise and cafeteria noise with both ascending and descending identification tasks. 


\section{TABLE V}

MEAN DATA RESULTS OF LISTENER JUDGEMENTS ON STETHOSCOPIC QUESTIONNAIRE

\begin{tabular}{|c|c|c|c|}
\hline SCALED LISTENER & & WH I TE & CAFETERIA \\
\hline JUDGEMENTS & QUIET & NOISE & NOISE \\
\hline
\end{tabular}

COMFORTABLE LOUDNESS LISTENING LEVEL

Acoustic

Amplified
3.88

$(1.02)$

4.33

$(1.08)$

NOISE NOISE

QUALITY AND CLEARNESS OF SOUND

Acoustic

Amplified

GOODNESS OF EAR TIP FIT

Acoustic

Amplified

EAR TIP NOISE ATTENUATION

Acoustic

Amplified

OVERALL IMPRESSION
3.72

$\frac{(1.07)}{4.77}$

$(0.42)$

2.50

10.921

2.83

(1.54)

Acoustic

Amplified

\begin{tabular}{ccc}
3.66 & 3.17 & 2.88 \\
$(0.84)$ & $(0.72)$ & $(0.90)$ \\
\hline 4.16 & 3.47 & 3.11 \\
$(1.04)$ & $(1.00)$ & $(1.02)$
\end{tabular}

$3.17 \quad 2.66$

$(0.88)$ $(1.02)$

$3.82 \quad 2.94$

$(0.80)$

$(0.93)$

ION OF THE INSTRUMENT

\begin{tabular}{ccc}
3.44 & 2.88 & 2.76 \\
$(0.98)$ & $(0.60)$ & $(0.75)$ \\
\hline 4.22 & 3.70 & 3.27 \\
$(0.94)$ & $(0.98)$ & $(1.12)$
\end{tabular}

Note: The means and standard deviations in parentheses of the raw data collection acquired from a stethscopic questionnaire evaluating the performance of the acoustic stethoscope and the amplified stethoscope in three listening environments, quiet, white noise and cafeteria noise. 
TABLE VI

DEPENDENT TWO-TAILED T-TEST ANALYSIS OF LISTENER JUDGEMENTS ON A STETHOSCOPIC QUESTIONNAIRE

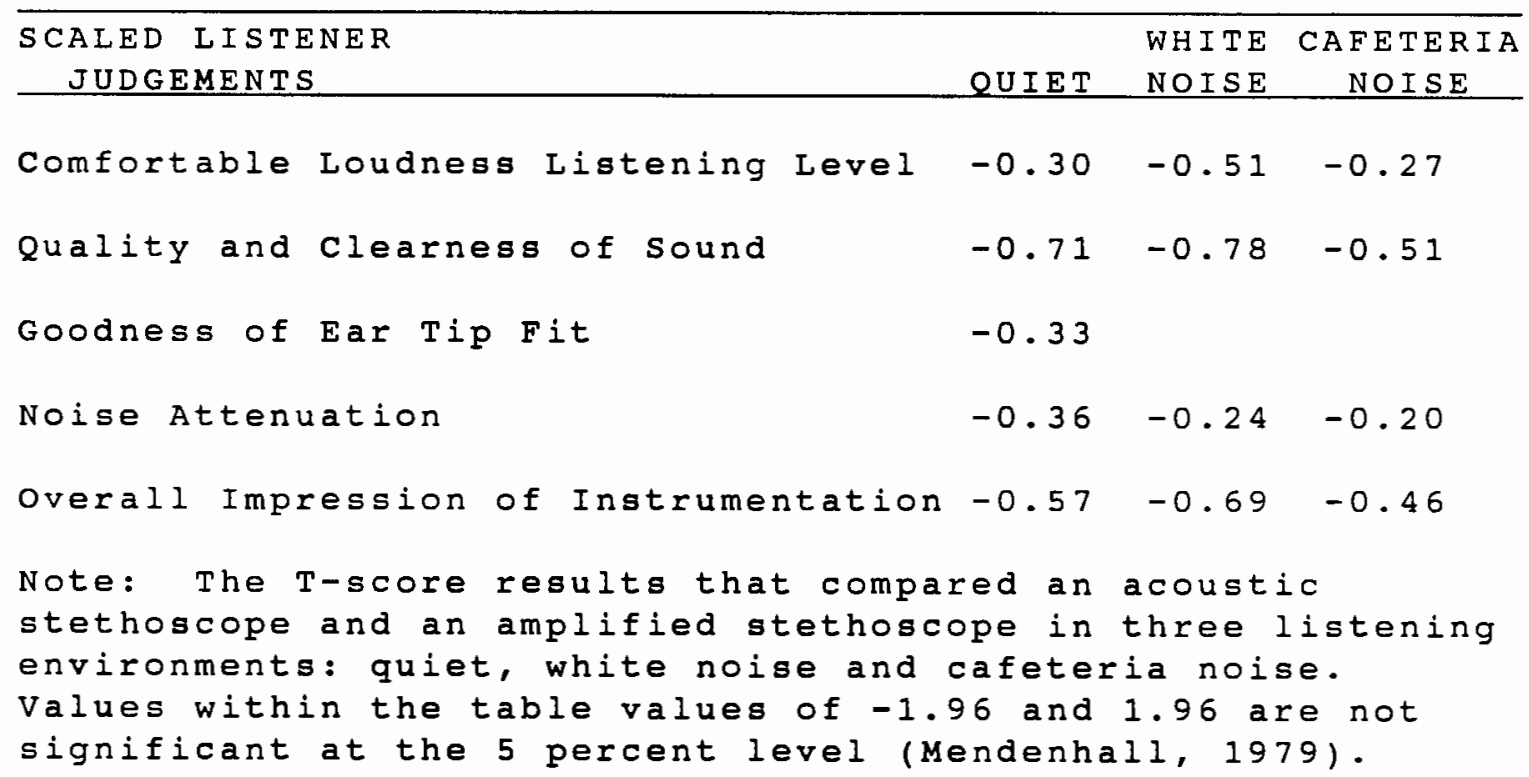




\section{DISCUSSION}

The primary objective of this study was to determine the EMLs for white noise and cafeteria noise during cardiac auscultation through two stethoscopes, an acoustic and anamplified. The most prominent result of the study revealed high EML means that ranged from 92 to 95 dBA for both noise environments during cardiac auscultation. These arithmetic means reflect the total noise level at the external ear which surpassed the ear tip attenuation to completely mask the heart sounds. The bilateral ear tip attenuation was measured in sound field in accordance with ANSI S12.6-1984 standard methodology by determining the thresholds of audibility for white noise and cafeteria noise, and then by subtracting the unoccluded values from the occluded values. The mean attenuation value of 8 dB HL for both noise environments and both stethoscopes was established.

The hospital noise study by shapiro and Berland (1972) reported noise levels ranging from 55 to 86 dBA. A comparison of these hospital noise levels and the EMI means, 92 to $95 \mathrm{dBA}$, show that there is a discrepancy between the two measured noise levels that range from 6 to 40 decibels. In affect, any noise exposure below the 86 dBA provides a negligible probability that the environmental noise will completely mask the auscultated heart sounds. However, at 
the extremes with 86 dBA background noise exposure and poor ear tip attenuation, there is a potential for the cardiac sounds to be effectively masked during auscultation. Moreover, it should be made clear that this was a detection task, and the effects of background noise on intelligibility of the heart sound signal was not encompassed in this study. This is an important point particularly in view of the probable noise interference effects on diagnostic auscultation.

The secondary objectives examined any potential EML differences between the acoustic stethoscope and the amplified stethoscope, and between the white noise and the cafeteria noise. These comparisons between the stethoscopes and the noise environments displayed results that were not significant at the .05 level. This would suggest that both stethoscopes were equally effective, and that both noise environments have equivalent masking capabilities at these high intensity levels.

Thirdly, the results from the subjective questionnaire data supported the objective results that there was no differentiation noted between either stethoscope in the two noise environments. Therefore, it appears that both stethoscopes perform equally well in the areas of comfortable loudness, quality and clearness of sound transmission, noise attenuation in both white noise and cafeteria noise, and goodness of ear tip fit. 
With the exception of one trial condition, the listener intra-reliability was very good, above a .50 Pearson $r$ coefficient. This suggests that the identification task was an absolute and stable measurement. In addition, the significance noted between the ascending and descending trials can also be considered as an afterthe-fact reliability check in that this significance was expected based on the psychophysical nature of the two methods (Green \& Swets, 1974; Egan \& Clarke, 1966).

The reason for the inordinately low correlation, .2225 Pearson $r$, of the amplified stethoscope during the ascending trials 3 and 4 in white noise can not be accounted for. Due to the randomized nature of the task presentation, no single factor should have exhibited an influence on one condition without affecting the other conditions. Based on the relatively high pearson $r$ correlations, none of the other conditions were affected. The possible internal

contaminating influences associated with the listener: attention, fatigue, and motivation, and external influential factors such as changes in ear tip fit which effect both noise attenuation and comfort, or changes in the loudness of other internal auscultated body sounds, were in affect counter-balanced for all conditions by the random presentation order. Thus, these internal and external influences can not assume the responsibility for generating the resultant correlation discrepancy. 
In conclusion, background noise levels of appropriate intensity will eventually and completely mask out the detection of heart sounds. The results from this study have quantitatively supported this observation for two noise environments during cardiac auscultation via two types of stethoscopes. At present, these EMLs appear to be higher then the average ambient noise levels in hospital settings. However, this finding does not eliminate the probability that noise interference is affecting the intelligibility of the heart sounds at lower intensity levels, those below the EMLs, during the auscultation process. 
CHAPTER V

SUMMARY AND IMPLICATIONS

\section{SUMMARY}

A basic relationship between stethoscopic auscultation and background noise interference was reviewed and examined in this study. The principle experimental design of the study questioned whether hospital background noise levels are capable of masking the threshold of detection for auscultated heart sounds. Several cited studies monitoring background noise levels in various hospital locations have reported averages exceeding the U.S. Environmental

Protection Agency (EPA) (1974) and world Health organization (WHO) (1980) recommendations of "quiet", namely 35 to 40 dBA (Falk \& Woods, 1973; Hilton, 1985, 1987; Shapiro \& Berland, 1972; Turner, et a1., 1975; Woods \& Falk, 1974) by as much as 46 to $51 \mathrm{~dB}$, i.e., up to 86 dBA (Shapiro \& Berland 1972). In addition to the previous query, a review of the literature reflected a lack of implementatory standards regarding the acoustic stethoscopic output and the masking effects of noise during the ausultation process. specifically, this study ascertained the effective masking level (EML) intensities of two noise environments, white 
noise and cafeteria noise, for cardiac auscultation through an acoustic stethoscope and an amplified stethoscope. Two principle measurements were employed in the experimental protocol: an objective measurement employing a method of adjustment detection identification task of the EML, and subjective responses solicited by a forced-choice questionnaire. Sixteen normal hearing listener's were selected to participate in the experiment. objective measures were analyzed using a MANOVA and a Pearson Product Moment coefficient of correlation. The subjective questionnaire data were analyzed with a two-tailed T-test. All analyses were based on a .05 level of confidence.

The resultant analysis of the experimental protocol data revealed calculated EML means greater than 92 dBA for both of the stethoscopes and the noise environments. These findings did not support the primary hypothesis which stated that there would be a relatively low, 65 to 75 dBA, EML for the two noise environments. Based on the these findings and previous noise studies, most hospital settings appear to provide a listening environment that will not completely mask the detection threshold of cardiac sounds during auscultation.

In addition, there were no significant differences demonstrated for the stethoscopes or the noise environments. This could be interpreted that the sprague-Rapport LAB 600 
acoustic stethoscope and the BOsch EST 40 amplified stethoscope function equally well for the detection purposes in high intensity, $90+d B A$, noige environments.

subsequently, at these high levels, there appears to be no discernable difference between the absolute masking effect of white noise and cafeteria noise. The questionnaire data results also found that there was no discernable difference between the subjective performance of the stethoscopes. Both stethoscopes were judged to perform equally well in the areas of comfortable loudnesa, quality and clearness of sound transmission, noise attenuation in both white noise and cafeteria noise, and goodness of ear tip fit.

\section{IMPLICATIONS}

The primary clinical disclosure of this study was the measured effective masking levels of heart sound detection in background noise during auscultation. This narrow range of the calculated EML means, 92 to 95 dBA, demonstrated the levels at which background noise effectively masked the detection of auscultated cardiac sounds. In addition, these noise levels are above the guidelines from the Environmental Protection Agency (EPA) that states that daily time weighted averages ( $T$ WA ) exceeding $85 \mathrm{dBA}$ are potentially hazardous to human hearing (Suter \& Von Gierke, 1987). Therefore, hospital noise levels should not exceed the TWA 85 dBA guidelines due to the potential that the noise will not only 
effectively mask the cardiac sounds but also create a damage risk situation for noise induced hearing loss among hospital workers continuously exposed.

The EML is at the uppermost region of the range for cardiac sound perception in background noise. Direct auscultation in quiet without a stethoscopic instrument might be hypothesized as the lowermost region of this range in that the perception of heart sounds is already very close to the threshold of human auditory detection (Groom, 1956, 1964; Williams \& Dodge, 1926). A probable linear progression of noise interference with the heart sound perception lies between these lower and uppermost regions. For example, diagnostic components of heart sounds may be masked, even though the heart beat is still audible. Although the reported hospital noise levels do not exceed the EML for cardiac sounds, there is the probability that these lower noise intensity levels may render the heart sounds diagnostically unintelligible. The present study did not address the noise interference level of heart sound intelligibility as perceived by experienced listeners, however, this topic is in need of further clarification. The hospital noise levels as reported by Falk and Woods (1973), Hilton (1985, 1987), Shapiro and Berland (1972), Turner, et al., (1975), and woods and Falk (1974) are below the mean EML of cardiac sounds in this study. This finding does not eliminate the possibility that these 
levels of background noise may mask other bodily sounds, such as pathologic cardiac sounds or respiration. other body sounds may have lower or higher EMLs then the cardiac sounds. Future research could follow suit with an investigation of the EML intensities for other auscultated body sounds.

Cafeteria noise and white noise were the artificial noises selected for this study because they are experimentally controllable stimuli. They may not approximate the environmental noiges from a medical facility. Although this study revealed no significant difference between the EMLs for the stethoscopes in the two noise environments, this does not eliminate the probability that other noise environments, either artificial, on site recordings, continuous or intermittent noises will have the same or different effectg.

Further investigation to provide more insight about auscultation in background noise might include the following areas: 1. What is the noise interference level for intelligibility of heart sounds in background noise, rather than detectability during cardiac auscultation for experienced 1 isteners? 2. Are the effective masking levels equivalent for other bodily sounds, such as respiration or pathological conditions? 3. Would other types of background noises display the same levels of interference, particularly intermittent noise and conversational noise? 


\section{REFERENCES}

American National standards Institute. (1973). Standard for Audiometers. (ANSI S3.6-1969 [R 1973]). New York:

American National standards Institute.

American National standards Institute. (1977). ANSI

s3.1-1977. New York: American National standards

Institute.

American National standards Institute. (1977). Criteria for permissible Ambient Noise during Audiometric Testing. (ANSI S3.6-1977). New York: American National Standards Institute.

American National standards Institute. (1983). American National standard specification for sound Level Meters. (ANSI S1.14-1983). New York: American National Standards Institute.

Chang, L., (1987). Development and Use of the stethoscope in Diagnosing Cardiac Digease. The American Journal of Cardiology, 60, 1378-1382.

Egan, J. P. \& Clarke F. R., (1966). Psychophysics and Signal Detection. In J. B. Sidowski (Ed.), Experimental Methods and Instrumentation in Psychology, New York: McGraw-Hill.

Ertel, P. Y., Lawrence, M., Brown, R. K., \& Stern, A. M. (1966a). Stethoscope acoustics: I. The doctor and his stethoscope. Circulation, 34, 889-898.

Ertel, P. Y., Lawrence, M., Brown, R. K., \& Stern, A. M. (1966b). Stethoscope acoustics: II. Transmission and filtration patterns. Circulation, 34, 899-909.

Falk, S.A., \& Woods, N. F. (1973). Hospital Noise - Levels and potential health hazards. The New England Journal of Medicine, Vol. 289, No. 15, 774-781.

Fredrick, H. A., \& Dodge, H. F. (1924). The stethophone, An electrical stethoscope. The Bell system Technical Journal, $3,531-549$. 
Gamble, C. J., \& Repologle, D. E. (1924). A multiple electrical stethoscope of teaching. Journal of American Medical Association, $\underline{82}, 387-388$.

Green, D. M., \& Swets, J. A. (1974). Signal Detection Theory and Psychophysics. New York: R.E. Krieger.

Groom, D. (1956). The effect of background noise on cardiac auscultation. American Heart Journal, 52,781-790.

Groom, D. and Chapman, W. (1959). Anatomic Variations of the Auditory Canal Pertaining to the Fit of stethoscope Earpieces. Circulation, 19, 606-608.

Groom, D. (1964). Comparative efficiency of stethoscopes. American Heart Journal, 68, 220-226.

Harris, C. M. (1979). Handbook of Noise Control (2nd Ed.). New York: McGraw-Hill.

Hilton, B. A., (1985). Noise in Acute Patient Care Areas. Research in Nursing \& Health, $8,283-291$.

Hilton, B. A., (1987). The Hospital Racket: How Noisy is Your Unit?, American Journal of Nursing, 87, 59-61.

Johnston, F. D., \& Kline, E. M. (1940). An acoustical study of the stethoscope. Archive of Internal Medicine, 65 , $328-339$.

Kindig, J. R., Beeson, R. P., Campbell, R. W., Andries, F., \& Tavel, M. (1982). Acoustical performance of the stethoscope: A comparative analysis. Curriculum in Cardiology, 104, 269-275.

Lipscomb, D. M. (1974). Noise: The Unwanted Sounds,

Chicago: Nelson Hall.

Littmann, D. (1972). Auscultation. American Journal of Nursing, $1239-1241$.

McKusick, V. A. (1958). Cardiovascular sound in Health and Disease. Baltimore: Williams \& Wilkins Company.

Melnick, W. (1985). Industrial Hearing Conservation. In J. Katz (Ed.), Handbook of Clinical Audiology, (3rd Ed.). Maryland: Williams \& Wilkins.

Mendenhall, W. (Ed.). (1979). Introduction to Probability and Statistics, (6th Ed.). Massachusetts: PWS Publishers. 
Miller, M. H. (Ed.). (1985). Council for Accreditation in occupational Hearing Conservation, (2nd Ed.). New Jersey: Association Management corporation.

Newby, H. A., \& Popelka, G. R. (1985). Audiology, (5thEd.). New Jersey: Prentice-Hall, Inc.

Oliver, S. R. A. (1989). In situ Measurements of Two Amplified and one Acoustic stethoscope (Masters dissertation). Oregon: Portland stateuniversity, speech \& Hearing sciences.

Peterson, A. P. G., \& Gross, E. E. Jr. (1967). Handbook of Noise Measurement, (6th Ed.). Massachusetts: General Radio Company.

Rappaport, M. B., \& Sprague, H. B. (1941). Physiologic and physical laws that govern auscultation, and their clinical application. The American society of America, 48, 1366-1372.

Rappaport, M.R., \& sprague, H. B. (1952). The Effects of Improper Fitting of stethoscope to Ears of Auscultatory Efficiency. American Heart Journal, 53 , $183-192$.

Sakula, A. (1981). RTH Laennec 1781-1826, His life and work: a bicentenary appreciation. Thorax, 36, 81-90.

Shapiro, R. A., \& Berland, T. (1972). Noise in the operating Room. The New England Journal of Medicine, 287, $1236-1238$.

Sheeley, E. C. (1978). Glossary. In J. Katz (Ed.), Handbook of clinical Audiology, (3rd Ed.). Maryland: Williams \& Wilkins.

suter, A. H. and H. E. Von Gierke. (1987). Noise and Public Policy. Ear and Hearing, 8 (4), 188-191.

Turner, A. G., King, C. H., \& Craddock, J. G. (1975). Hospitals, Vol. 49 , No. $15,85-90$.

U.S. Environmental Protection Agency, (1974). Information on levels of environmental noise requisite to protect public health and welfare with an adequate margin safety (Report \#550-9-74-004), Washington, D.C. 
Williams, W. \& Dodge, M. (1926). The frequency

characteristics of heartbeat sounds. The Journal of

the American Medical Association, 85, 1584-1589.

Woods, N. F., \& Falk, S. A. (1974). Noise stimuli in the Acute Care Area. Nursing Research, Vol. 23, No. 2, 144-150.

World Health Organization, (1980). Noise. Geneva: WHo.

Yost, W. A., \& Nielsen, D. W. (1985). Fundamentals of Hearing: An Introduction, (2nd Ed.). New York: CBS College Publishing. 
APPENDIX A

STETHOSCOPIC QUESTIONNAIRE

Rate the stethoscope in each environment on the following 5-point scale:

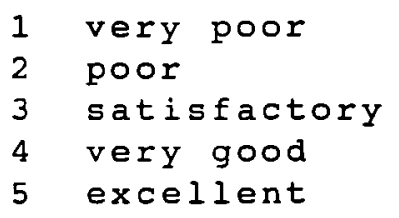

HEART SOUNDS IN :

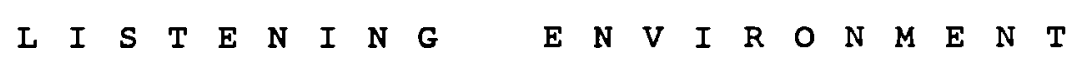

QUIET

WHITE NOISE

CAFETERIA NOISE

Is the heart sound at a comfortable loudness listening

level?

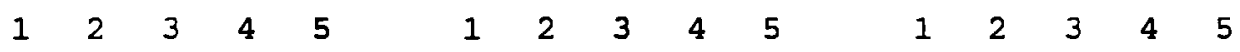

\begin{tabular}{|c|}
\hline 2 \\
\hline
\end{tabular}

How is the general quality and clearness of the heart sound?

How well do the ear tips fit?

$\begin{array}{lllll}1 & 2 & 3 & 4 & 5\end{array}$

How well do the ear tips attenuate the noise?

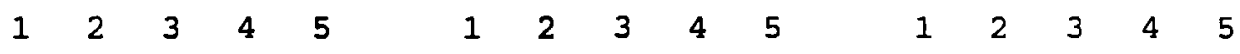

What is your overall impression of the instrument?

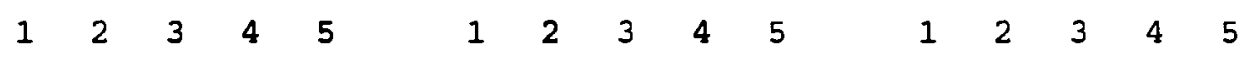




\title{
APPENDIX B
}

\section{INFORMED CONSENT}

\begin{abstract}
I,
hereby agree to

serve as a subject in the research project entitled "A comparison of an Acoustic stethoscope and an Amplified stethoscope in white noise and cafeteria noise during cardiac auscultation" conducted by principal investigator Lynda Lynell Gigstad, Graduate student in Audiology at Portland state University and Drs. James Maurer and Thomas Dolan, Audiologists and Faculty members.

I understand that the study involves the use of and written evaluation of two stethoscopes, an acoustic stethoscope and an amplified stethoscope, during cardiac auscultation in which I will adjust the noise level.

I understand that no known risks are associated with
\end{abstract} these procedures. It has been explained to me that the purpose of the study is to provide new knowledge about stethoscopic auscultation in background noise.

I may not receive any direct benefit from participation in this study, but my participation may help to increase knowledge which may benefit others in the future.

Lynda Lynell Gigstad and Drs. Maurer and Dolan have offered to answer any questions I may have about the study, and what is expected of me in the study. I have been assured that all information I give will be kept confidential and neither my name nor identity will be used for publication or public discussion purposes.

I understand that I am free to withdraw from participation in this study at any time without jeopardizing my course grade or my relationship with portland state University.

I have read and understand the foregoing information and agree to participate in this study.

Date Signature

If you experience problems that are the result of your participation in this study, please contact the secretary of the Human subjects Research Review committee, office of Grants and Contracts, 303 Crammer Hall, Portland state University, 464-3417. 